\title{
EPITHELIAL INLAY WITH KERR-MATERIAL TO FORM AN EYE-SOCKET*
}

BY

IDA CZUKRÁSZ, M.D.

(FROM THE UNIVERSITY EYE CLINIC, DEBRECEN, UNDER the charge of Professor A. Kreiker)

No doubt, the formation of an eye-socket is a hard problem in ophthalmic surgery. There are numerous methods of making a hollow to fit the prosthesis. Essentially, all methods are the same in principle. Mostly epithlial inlay is used. Only the procedure in fitting it to the double-walled hollow is different. The rigid models of glass, metal, and horn were not satisfactory. They are not plastic, unmouldable, and so do not lend themselves enough to the variable cases. A new and very good method is that of Csapody. The form of his instrument can be adjusted upward and downward. He reports satisfactory results. It has some advantages indeed. By closing the two arms, one can put it in and take it out more easily, and during the post-operative treatment a pressure into the hollow can be exercised at pleasure. But still it is not so individualistic that the instrument can adapt itself entirely to the shape of the cavity.

The only method answering to this claim, which Esser first proposed in 1912, is little known and very seldom used. The Stent-material has long been well known in stomatology. But it can be, as Esser showed, very useful in general-surgery as an aid for socket-plastics. His articles have been published in Vol. XXVII of Technique Chirurgical and in Vol. CLXXIX of Annales d'Oculistique. However, it is not mentioned in handbooks or in the text-books of Ophthalmic-surgery except in the lately published " Eingriffe am Auge" by L. v. Blaskovics and A. Kreiker. There the method is described with all its details.

The principle of the method is to get the exact impression of the prepared hollow with Stent-material, which can be softened in hot water and stiffens at body temperature. This mould, showing the anatomical form of the cavity, will be the temporary prosthesis, the support to keep the inlay on its place. A one-piece flap, as in Esser's article, or a graft of more pieces can be employed.

In our opinion, its greatest advantage does not lie in the exact adaptation of the flap which provides for the adhesion and nutrition, but the fact that with its help, the inlay can be fixed circularly

\footnotetext{
* Read before the Hungarian Ophthalmological Society, October 1, 1938.
} 
to the bony orbital margin. This avoids effectually and definitely the post-operative shrinking. We have to make the hollow by cutting with the knife circularly to the bone so that the cavity will extend really to the bony margin. Naturally the mould takes this form exactly, therefore the flap is also fixed circularly to the bone.

It has one disadvantage, according to Csapody's method, that is, that a large canthotomy is necessary. Otherwise we might have difficulty with the putting in and taking out of the mould. But this is not of great importance, as it is richly compensated by the nice and permanent result.

We tried this method in the Eye-clinic of Debrecen in two cases. Here I wish to show with pictures the later results of them.

\section{Case I}

This was a man aged 21 years, who had lost his eye when three years old. A prosthesis was never worn, so the conjunctival sac shrank. A plastic socket-operation had been done elsewhere in March, 1937, without any result, properly said, with a final and total symblepharon. He came to us on August 25, 1938 (Fig. 1a). After the solution of the symblepharon, we extirpated all the remaining conjunctiva and some of the scarred tissue. (It is important that there shall not remain any conjunctiva, to avoid every disadvantage of the heterotopy.) By preparing up and down to the bony orbital margin, to the internal and external canthus, we made a cavity. At the same time a large canthotomy was made.

Instead of Stent's material, we employed Kerr's mass which is of the same nature. A plate of it, softened in $45^{\circ}$ Centigrade normal saline solution, was pressed into the cavity so that it became an exact fit.

From the interior surface of the right leg, a half thickness skingraft was taken, laid on the mould, and without any pressure placed in the hollow. When arranging the lids, a superfluous strip of the graft, $1 \mathrm{~cm}$. in width, hung over. This we took away and replaced on the wound of the leg. No sutures were necessary.

Three days later the dressing was changed. The graft was living in toto. Ten days later the mould was removed. Then ten more days vaseline-bandage, and when the stratum corneum of the transplantation renewed, a simple glass prosthesis was placed in the well-fitting socket.

As Fig. $1 c$ shows, 6 weeks later, the result is very nice. A wide socket which holds the glass-bulb correctly is to be seen. The result is not final. We have to sew up the canthotomy, and 


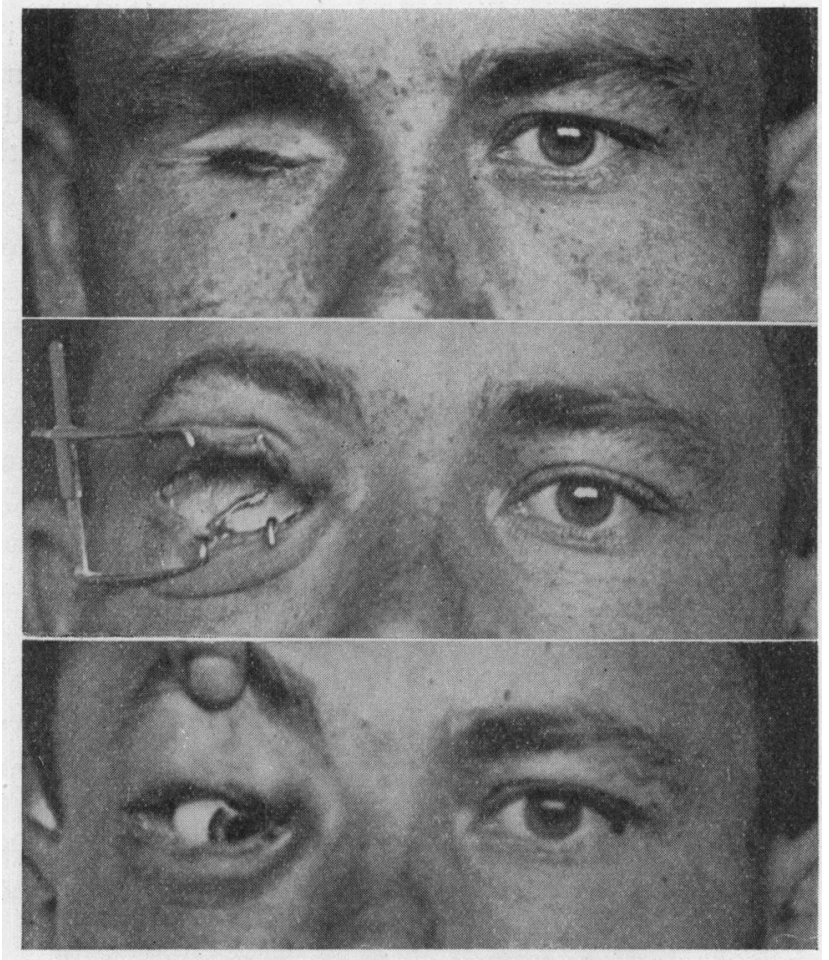

a.

perhaps there will be a need of some folding-sutures after Blaskovics, to put the upper lid in the right position-because in the foregoing operation all the muscles were taken away.

\section{Case II}

A twenty year old man had an accident to the right eye when 9 years old. A disfiguring symblepharon was caused. We operated September 7, 1936, for the symblepharon (a mucous membrane plastic taken from the mouth) without any result. In January, 1937, we decided to enucleate the eye and take all the remaining conjunctiva out, because we thought to get later on a good result with an epithelial-inlay. After the lid-margins were healed together, on April 17, 1937, we produced a socket as above described. We took the flap also from the leg, but this time a 
Thiersch-graft of $5 \times 10 \mathrm{~cm}$. Kerr-mould was removed on the 7th day after the operation, and a glass prosthesis put in instead. Two months later we gave a correction to the external canthus.

Fig. 2 shows the final solution of the problem one and a half years later. The socket is well formed and with the prosthesis it gives a perfect cosmetic effect.

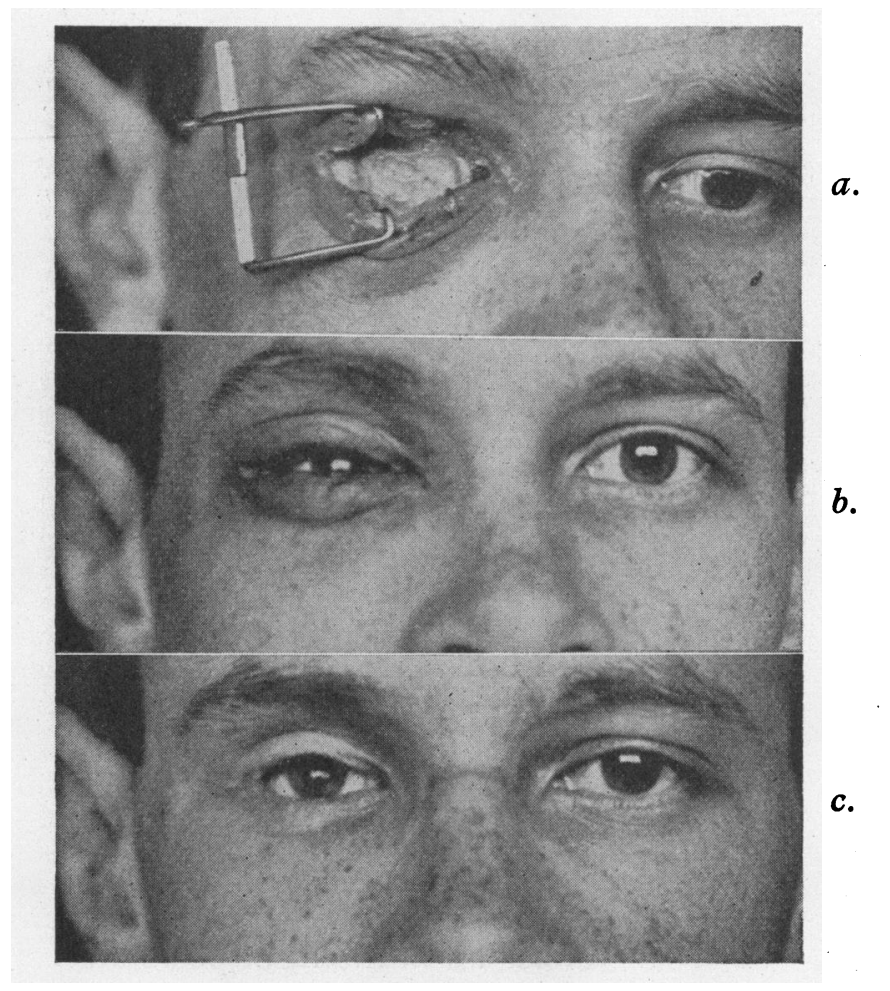

FIG. 2.

a. Eye-socket.

b. Fitting prosthesis 6 weeks after the operation.

c. Fitting the prosthesis one and half years after the operation.

It is all the same what kind of an inlay is employed. Thierschgraft or half-thickness skin-flap can give the same perfect result. There is no difference in the post-operative treatment except the few more days which we need for the dressing of the latter.

In Fig. 3 is shown the transsection of the operation. It is to be seen that the socket has to reach the bone. The Kerr-impression stiffens in a few minutes in the cavity. After being removed, it is covered with Thiersch-graft, so that the connecting edge shall 


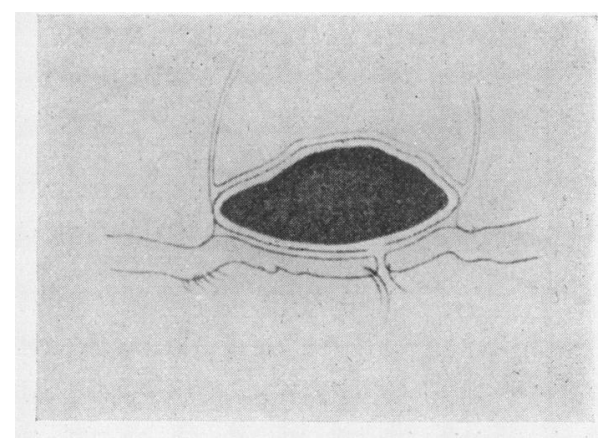

FIG. 3.

Transsection of the mould.

be in the eyelid-fissure. When 8-10 days have lapsed, the mould is finally removed.

The method satisfies all the claims of a plastic-operation. We can adapt it to any case in any circumstance and it can be performed simply in a short time.

\section{LITERATURE}

Esser.-Zentralbl. $f$. d. ges. Ophthal., Vol. XXXVI.

Zentralbl.f. d. ges. Ophthal., Vol. XXXV.

CsAPODY.-Zeitschr. $f$. Augenheilk., Vol. LXXXVII.

Zeitschr. f. Augenheilk., Vol. XCIV.

Blaskovics-Kreiker.-Eingriffe am Auge. Ferd. Enke, Stuttgart, 1938.

\section{A CASE OF PRIMARY LUES IN THE SUPERIOR FORNIX*}

\section{BY}

IDA CZUKRÁSZ, M.D.

(FROM THE UNIVERSITY EYE CLINIC, DEBRECEN, UNDER THE CHARGE OF PROFESSOR A. KREIKER)

I HERE wish to give a report on a forty year old physician, who called at the clinic on February 8th, 1938.

On January 2nd this year, as he told us, one of his patients who was suffering from plaques muqueses coughed into his right eye. A week-or so before, that is to say four weeks after the occurrence, his right eye became swollen, the conjunctiva red and the preauricular lymph glands infiltrated. No compresses or any astringent material helped, so he thought of luetic infection.

\footnotetext{
* Read before the Hungarian Ophthalmological Society, October 2, 1938.
} 